\title{
O RITMO DO JAPONÊS E A UNIDADE HAKU PROPOSTA POR BEKKU ${ }^{1}$
}

Elza Taeko Doi

RESUMO: Este artigo tem como objetivo discutir a proposta de Bekku (1977) sobre o ritmo do japonês baseada na unidade bimoraica, distinta daquela tradicional definida em termos de grupos formados de 5 e 7 moras.

ABSTRACT: The aim of this paper is to discuss the analysis of Japanese rhythm regarding a bimoraic unit proposed by Bekku (1977) which differs from the traditional definition based on groups of five and seven morae.

PALAVRAS-CHAVE: fonologia do japonês; mora; ritmo; bimoraicidade.

KEYWORDS: japanese phonology; mora; rhythm; bimoraicity.

\section{Introdução}

Este trabalho tem como objetivo discutir a proposta de Bekku (1977) relacionada com a sistematização da estrutura rítmica do japonês. Diferentemente das propostas que definem o ritmo do japonês como moraico, em que se leva em conta apenas a unidade do ritmo sem determinar a sua estrutura e a sua organização, seu interesse está em determinar o padrão rítmico da língua baseado em quatro unidades moraicas, divisíveis em dois grupos de duas moras. A análise de Bekku, de caráter empírico,

1. Este trabalho resume um dos capítulos da Tese de doutorado "O Papel da Sílaba e da Mora na Organização Rítmica do Japonês” desenvolvida no Instituto de Estudos da Linguagem, Unicamp, 1997. 
aborda o ritmo do japonês dentro de uma "conceituação cultural sobre os quatro tempos rítmicos"

\title{
2. O Grupo Rítmico Formado de Sete e Cinco Moras
}

Segundo Bekku (1977), o ritmo do japonês é, comumente, definido na lingüística tradicional japonesa em termos de moras e do número de unidades que constituem os grupos (formados de cinco e sete moras) que se realizam alternadamente dentro de um enunciado. É através dessa caracterização que se define o ritmo dos poemas do japonês, como por exemplo o Tanka, composto de cinco, sete, cinco, sete e sete moras; e o Haiku, composto de cinco, sete e cinco moras.

Considera-se que as realizações em japonês que refletem uma euritmia são, em sua grande maioria, compostas por esse ritmo formado de cinco e sete unidades moraicas. É o que acontece, por exemplo, nos provérbios, máximas e nas observações de alerta do trânsito:

\author{
Yuki ya koori mo / moto wa mizu $(7,5)$ \\ 'Tanto a neve quanto o gelo se originam da água' \\ Tsugi ni deru / aoshingo de / watarimashoo $(5,7,6)^{2}$ \\ 'Vamos atravessar no próximo sinal verde'
}

Segundo o autor, a expressão formal do poema se daria, em princípio, através da rima e do ritmo. A rima, resultante do efeito dos sons no início ou no fim das palavras, é facilmente verificável nos poemas ocidentais e chineses, mas no japonês ela não traria um efeito expressivo dada a característica das sílabas abertas da língua, portanto, facilmente combináveis, e dado o número restrito de vogais (apenas cinco) que resultaria em uma simplicidade e uniformidade na rima. As marcações consonantais em início de palavras também não oferecem efeitos de aliteração porque as consoantes iniciais da sílaba do japonês não são "fortes" (tensas) o suficiente para marcar uma expressividade. Não se verifica também a repetição de uma determinada combinação durativa resultante da relação entre unidades longas e breves, presente nos poemas do latim clássico. $\mathrm{O}$ poema do japonês terá, assim, apenas o ritmo como elemento de expressão formal. Considerando o ritmo como repetição regular de um padrão, no caso do japonês, esse padrão poderia ser buscado apenas no número de moras, uma vez que os acentos se caracterizam pela oposição Alto e Baixo e são apenas distintivos.

Para Sotoyama (apud Bekku, op. cit., p. 43), o estilo composto por cinco e sete moras não representa, na realidade, um ritmo: não é o ritmo melódico de tons altos e baixos, nem tampouco um ritmo caracterizado pela duração das vogais como acontecia com o grego clássico. Mostra apenas uma relação definida na extensão entre as cadeias formadas por sete e cinco moras. Segundo Bekku, a definição do ritmo baseada apenas

2. É um caso de jiamari (lit. sobra de letra), em que se permite um pequeno desvio no número das unidades. 
em números seria irrelevante porque qualquer número de moras poderia representar um ritmo. O importante, segundo o autor, seria averiguar a preferência dos falantes da língua por esse ritmo representado pela alternância de seqüências compostas por cinco e sete moras. $\mathrm{O}$ argumento apresentado por Bekku a essa preferência se baseia no número de itens lexicais do japonês: cerca de $60 \%$ são constituídos por palavras formadas de duas moras (representados por dois kana) e seus múltiplos, e cerca de $30 \%$ são constituídos de itens lexicais formados de três moras (três kana).

As palavras formadas por duas moras constituem em sua maioria o vocabulário básico da língua, como podemos verificar em: yama "montanha" kawa "rio" sora "céu", tsuti "terra", titi "pai", haha "mãe", haru "primavera", natsu "verão", aki "outono" fuyu "inverno" hito "pessoa" (p. 53). Segundo o autor, isto seria um indicativo de que o conjunto de duas moras seria a unidade mais natural e de fácil pronúncia no japonês. Conforme Kindaichi (1970), como uma unidade silábica em japonês se caracteriza por uma realização breve ${ }^{3}$, uma palavra monomoraica acaba sendo de difícil pronúncia não somente pela presença de vários homófonos, mas também porque não há "acomodação auditiva e rítmica" gerando, não raras vezes, incompreensões na comunicação. Casos freqüentes de acréscimo de prefixos de polidez em palavras monomoraicas como oyu (para $y u$ "água quente"); osu (para su "vinagre") até mesmo por aqueles que rejeitam a linguagem feminina, refletem as estratégias a que os falantes recorrem para sanar a dificuldade na realização de palavras monomoraicas.

Bekku define o grupo rítmico do japonês como formado por dois haku, cada haku composto de duas moras. Para ele, esse grupo rítmico constitui a base para a determinação da preferência dos japoneses para o ritmo comumente definido em 5 e 7 moras.

Exemplificando a proposta de Bekku em um haiku como:

$$
\begin{aligned}
& \text { Furuikeya "velho lago" (5 moras) } \\
& \text { Kawazu tobikomu "uma rã salta" ( } 7 \text { moras) } \\
& \text { Mizu no oto "barulho da água" (5 moras) }
\end{aligned}
$$

a segmentação adquire a seguinte feição:

$$
\begin{aligned}
& \text { fu.ru.i.ke/ya. } 0.0 .0 / \\
& \text { ka.wa.zu. 0/to.bi.ko.mu/ } \\
& \text { mi.zu.no. 0/o.to. } 0 \text { 0/ }
\end{aligned}
$$

No primeiro verso furuikeya, a palavra furuike de quatro moras (que correspondem a quatro tempos, definidos como unidades virtuais) forma um grupo rítmico seguido de um outro grupo formado por uma mora ya mais três pausas (três tempos virtuais), ocupando um total de quatro tempos; no segundo verso, kawazu (três moras) forma um

3. Em oposição à realização das palavras em inglês como rhythm, start e sphinx, consideradas monossilábicas (Bekku, op. cit., p. 52). 
grupo rítmico em conjunto com uma pausa, seguido de um outro grupo tobikomu (quatro moras); no terceiro verso, mizuno forma um grupo rítmico em conjunto com uma pausa e oto forma um outro grupo rítmico com mais duas pausas.

Esta segmentação, no entanto, reflete a leitura oral do haiku segundo uma melodia apropriada para tal, cujos recursos lingüísticos para expressão da emotividade como "ya" exigem certamente uma pausa mais longa. Nesse sentido, não se poderia dizer que o mesmo ocorra na fala comum, embora os traços rítmicos sejam preservados.

Assim, se realizarmos a frase "kawazu tobikomu mizu no oto" em um ritmo da fala considerada "normal" ela poderia ser representada como segue:

ka.wa.zu. / .to.bi.ko.mu./ mi.zu.no.o.to.

A inserção das pausas se justifica, segundo Bekku, para dar uma organização baseada em quatro tempos, porque "os japoneses buscam, intuitivamente, um ritmo de quatro tempos” (Bekku, op. cit., p. 68). É nesse sentido, continua Bekku, que após um verso de cinco moras, se inserem longas pausas para formar um ritmo de quatro tempos.

Quanto à questão da escolha de cinco e sete sons (moras) para formar o ritmo de quatro tempos, Bekku afirma que, na realidade, esse número seria resultante da combinação mais freqüente das palavras do japonês.

Dada a necessidade de se recorrer ao uso de partículas relacionais (em sua maioria constituídas de uma ou duas moras) e considerando-se também a flexão dos verbos, cada grupo rítmico do japonês acaba atingindo um número aproximado e variável de cinco a sete moras. Tomando como base as palavras formadas de três e duas moras, ilustraremos abaixo a organização do ritmo baseada na proposta acima de Bekku.

$$
\begin{aligned}
& \text { a.si.ta.wa / da.re.to // da.i.ga.ku.e // i.ki.ma.su.ka } \\
& \begin{array}{cccc}
3+1 & 2+1 & 4+1 & 4+1
\end{array}
\end{aligned}
$$

\footnotetext{
"Com quem (você) vai à universidade amanhã?"

asita "amanhã";

$w a$ (partícula que indica tópico);

dare "quem"; to (partícula que indica companhia) "com";

da.i.ga.ku "universidade";

$e$ (partícula que indica direção) "a";

$i k i$ (verbo) "ir";

masu (auxiliar de verbo que expressa polidez, tempo presente e futuro);

$k a$ (partícula que indica interrogação).
}

Embora esta sistematização venha refletir basicamente a organização do ritmo do japonês, sabemos que, na fala normal, as realizações não ocorrem como foi apresentado acima, em termos numéricos. Mesmo que se considere a alta porcentagem de itens lexicais compostos por duas moras, percebemos a presença de um "arranjo" para adequar a organização rítmica que se quer propor como, por exemplo, postular várias pausas para atingir o número de sílabas necessárias para dar conta do ritmo. 
Diferentemente da definição tradicional do ritmo do japonês baseada em cinco e sete moras que representa apenas uma alternância de unidades formadas por cinco e sete moras, a proposta de Bekku, na medida em que procura definir a unidade rítmica da língua em termos de haku bimoraico, constitui um primeiro passo para a caracterização do ritmo do japonês.

\section{Haku, a Unidade Bimoraica}

Para Bekku, a divisão de uma palavra em grupos formados de duas moras (um $h a k u$, na denominação do autor) corresponderia à silabificação das línguas estrangeiras. A diferença, segundo o autor, está em que enquanto a silabificação se relaciona com as sílabas, no caso do japonês a divisão se baseia em haku, formada por duas moras. Diferentemente de Kindaichi que considera um haku como correspondente a uma mora, para Bekku, a unidade bimoraica constitui um haku.

A organização de haku se faz a partir do começo da palavra, marcando a divisão de duas em duas moras. Ex.:

$$
\begin{array}{ll}
\text { sakura "cerejeira" } & >\text { saku/ra/ } \\
\text { murasaki "roxo" } & >\text { mura/saki/ } \\
\text { kurisumasu "natal" } & >\text { kuri/suma/su/ }
\end{array}
$$

Nas palavras compostas formadas por duas palavras de duas moras:

$$
\begin{array}{ll}
\text { daikoN "nabo" } & >\text { dai/koN/ } \\
\text { kanadzuti "martelo" } & >\text { kana/dzuti/ }
\end{array}
$$

(Bekku, op. cit., pp. 56-57)

No caso de compostos formados pela primeira palavra monossilábica e a segunda polissilábica, a divisão se faz com base na contagem das moras; no caso em que as duas palavras são polissilábicas, a divisão em haku é feita ou pelo número de moras a contar do início, ou pela consideração de cada item lexical, separando a palavra pelo conteúdo semântico ${ }^{4}$. Assim, as palavras abaixo podem ser segmentadas em dois tipos: pelo número de moras, isto é, pelo haku, e pelo significado (Bekku, op. cit., pp. 50-60).

$\begin{array}{lll} & \text { haku } & \text { significado } \\ \text { sakurasoo "prímula" } & \text { saku-raso-o } & \text { saku-ra-soo } \\ \text { sakurairo "cor de rosa claro" } & \text { saku-rai-ro } & \text { saku-ra-iro } \\ \text { sakuramoti "tipo de doce" } & \text { saku-ramo-ti } & \text { saku-ra-moti } \\ \text { sakurajima "Sakurajima" (ilha) } & \text { saku-raji-ma } & \text { saku-ra-jima }\end{array}$

4. Estes dados que permitem uma dupla segmentação seriam, segundo Bekku, resultantes da influência da "sensação, do estado de espírito e do ambiente" (Bekku, 1977, p. 60) do momento em que o falante realiza esse tipo de palavras. Esse comentário de caráter subjetivo reflete a natureza do livro, que se 
Com relação aos casos em que a primeira palavra monomoraica forma um haku junto com a palavra seguinte, Bekku afirma que isso seria um indicativo de que o japonês evita a realização de um haku monomoraico na cabeça da palavra.

O caso de uma colegial, comentado por Bekku, que não conseguiu dar continuidade à leitura da palavra "dorutomunto" (nome de uma cidade) após a realização de "dorutomu" porque a unidade seguinte começava por uma mora não plena nasal, mostra a dificuldade de se pronunciar uma unidade que começa com uma mora não plena. No entanto, algumas páginas à frente, Bekku afirma que em japonês é possível a realização de haku que se inicia por uma mora não-plena como por exemplo em:

$\begin{array}{ll}\text { kariNtoo "tipo de biscoito" } & \text { kari/Nto/o } \\ \text { mikaNyama "montanha de laranjas" } & \mathrm{mika} / \mathrm{Nya} / \mathrm{ma} \\ \text { futoppara "corajoso" } & \text { futo/ppa/ra } \\ \text { mieppari "vaidoso" } & \mathrm{mie} / \mathrm{ppa} / \mathrm{ri} \\ \text { obeNtoo "lanche" } & \text { obe/Nto/o }\end{array}$

Consideramos que estas segmentações são possíveis apenas em realizações enfáticas ou quando se quer soletrar uma palavra sem levar em conta a organização rítmica da mesma. Essas realizações constituem, portanto, casos especiais de fala e não refletem a realidade fonológica nem representam a intuição do falante nativo.

Essas considerações de Bekku acarretam alguns problemas, como veremos a seguir.

Quando um dos membros do composto é formado por uma palavra monomoraica ou por um prefixo monomoraico e esse composto é constituído apenas por moras plenas como em:

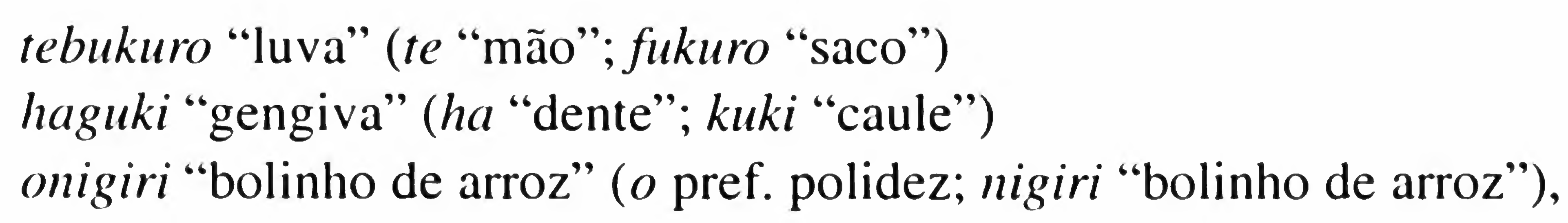

a divisão em $h a k u$ formado por duas moras, da esquerda para a direita, atende à intuição do falante da língua. Entretanto, quando o primeiro haku do segundo membro do composto envolve uma mora não plena, a divisão em haku bimoraico passa a ser não adequada em termos de intuição do falante e da estrutura fonológica da língua, embora Bekku afirme o contrário, como vimos nos exemplos kariNtoo, mikaNyama, futoppara e mieppari, acima.

Os compostos formados por palavras de duas e três moras ou de três e duas moras admitem, segundo Bekku, divisões baseadas em haku e em significado das palavras. Entretanto, consideramos que a divisão baseada em haku que leva em conta a segmentação em grupos de duas moras, sem envolver quaisquer informações fonológicas e morfológicas, acarreta resultados inadequados em termos de estrutura fonológica da língua.

caracteriza pelas observações empíricas ricas e inspiradoras, embora as considerações lingüísticas ali feitas não permitam uma descrição objetiva dos fatos. 
Tomando os mesmos exemplos de Bekku elencados acima, podemos dizer que no caso de sakurasoo, o elemento soo não poderia ser dividido em so-o porque ele forma um haku independente composto por uma sílaba pesada (formada de mora plena /so/ e uma mora não plena /o/); no caso de sakurajima, a sonorização da consoante inicial da segunda palavra (shima), indica que jima constitui uma palavra independente, o que significa que jima constitui um domínio distinto de sakura na segmentação em haku. Para os outros exemplos sakurairo e sakuramoti, devem ser consideradas as informações morfológicas, porque o segundo membro consiste de uma palavra polimoraica de conteúdo.

\section{Considerações Finais}

Embora desenvolvida totalmente em bases empíricas, a definição de ritmo de Bekku apresenta uma inovação no tratamento do ritmo do japonês.

Ao propor a presença das pausas em poemas, Bekku pretende mostrar que o ritmo básico do japonês é quadrimoraico, mesmo que algumas dessas moras sejam um reflexo de uma pausa virtual. A partir desse pressuposto, ele afirma que as formas compostas por cinco e sete moras que se caracterizam por uma euritmia são, na realidade, formadas por unidades compostas por quatro tempos moraicos. O grupo rítmico formado por quatro moras que se organiza em dois haku bimoraicos já reflete uma estrutura rítmica.

Embora a proposta de unidade bimoraica tenha tido como objetivo dar uma explicação para a preferência dos japoneses pela organização de grupos frasais formados por cinco e sete moras, a proposta de Bekku possui o mérito de delinear uma estruturação rítmica do enunciado do japonês, uma proposta diferente da definição do ritmo em termos moraicos. Destacamos, no entanto, dois aspectos que consideramos problemáticos na proposta de Bekku:

- a construção mecânica das unidades bimoraicas a partir do início da palavra; e,

- a dupla possibilidade de segmentação das palavras compostas formadas por palavras de duas e três moras.

Podemos dizer que estes dois casos resultam, de um lado, da ausência de critérios para a segmentação de uma palavra (ou melhor, para a construção das unidades bimoraicas) e, de outro lado, da falta de uma determinação do domínio de construção dessas unidades bimoraicas. A falta de uma caracterização mais detalhada das unidades bimoraicas gera casos de segmentação que vão contra a intuição do falante e contra a estrutura fonológica da língua como aqueles discutidos com relação aos exemplos que envolvem as moras não plenas na posição inicial do haku. O segundo aspecto, relacionado com as palavras compostas, decorre da indeterminação do domínio em que os haku são construídos. As duas possibilidades de segmentação, baseadas no número de moras e no significado das palavras, mostram que no primeiro caso a palavra composta é apreendida como um todo, enquanto que, no segundo caso, os membros do composto são considerados como palavras distintas. 
Como o objetivo deste trabalho foi o de apresentar a proposta de Bekku (1977), por si só inovadora no que se refere ao ritmo do japonês, limitamo-nos a fazer as observações que merecem uma maior reflexão, segundo a perspectiva que adotamos em Doi (1997).

\section{Bibliografia}

BEKKU, Sadamori. Nihongo no Rizumu (O Ritmo do Japonês). Tokyo, Kodansha, 1977.

DoI, Elza T. O Papel da Sílaba e da Mora na Organização Rítmica do Japonês. Campinas, Unicamp. Tese de Doutorado, 1997.

KINDAICHI, Haruhiko. Nihongo On-in no Kenkyu (Estudos sobre a Fonologia do Japonês). Tokyo, Tokyodo, 1967. . Nippongo (Lingua Japonesa). Tokyo, Iwanami, 1970 [1975]. 